\title{
Stathmin is expressed by the proliferating hepatocytes during liver regeneration
}

\author{
D C Rowlands, R F Harrison, N A Jones, A Williams, S G Hubscher, G Brown
}

\begin{abstract}
Aim-To determine the liver cell populations that express the phylogenetically conserved cytosolic protein stathmin during liver regeneration.

Methods-Double immunostaining for stathmin and the Ki67 antigen was performed on sections of formaldehyde fixed, paraffin wax embedded tissues from 31 liver specimens. These included a variety of disease conditions characterised by some degree of hepatocyte regeneration. Quantitative western blot analysis was performed on 22 of these specimens.

Results-Variable amounts of stathmin protein were detected by western blotting in all of the specimens examined. Stathmin was not detected in three cases of histologically normal liver. On immunostaining, stathmin was demonstrated in a proportion of hepatocytes as well as lymphoid inflammatory cells and other tissue elements. In all cases most of these stathmin positive cells showed nuclear positivity for the Ki67 antigen.

Conclusions-Stathmin is expressed by proliferating hepatocytes but not by resting hepatocytes. Thus, it is likely that the protein has a function important to cell proliferation as opposed to cell differentiation.
\end{abstract}

(f Clin Pathol: Mol Pathol 1995;48:M88-M92)

Keywords: Stathmin, p19, prosolin, metablastin, LAP18, liver, proliferation.

Stathmin is a $19 \mathrm{kDa}$ cytosolic protein that has been described by several independent groups. This protein has been called prosolin, ${ }^{1}$ p19 or metablastin, ${ }^{2} 19 \mathrm{~K},{ }^{3}$ p18 or Op $18,{ }^{4}$ pp $21 / \mathrm{pp} 23,{ }^{5}$ and Lap $18^{6}$ in addition to stathmin. ${ }^{7}$ The complementary DNA (cDNA) and the protein sequence show a high degree of phylogenetic conservation. ${ }^{8}$ The protein can constitute up to $0.5 \%$ of total cytosolic protein. ${ }^{1}$ The function of stathmin is undetermined, although on the basis of the level of expression and changes in the state of phosphorylation it has been proposed that the protein is important in a wide range of processes including hormone secretion, cell differentiation, development and cell proliferation. ${ }^{7}$ It has been suggested that the protein has a wide role in signal transduction. ${ }^{7}$ In addition, stathmin concentrations were found to be raised in a variety of neoplastic cells and some groups consider that the protein has a role in malignant transformation. ${ }^{489}$

The use of polyclonal antisera that recognise stathmin for immunohistochemical staining of normal tissues demonstrate that, in most cell lineages, expression of the protein is confined to cell populations that are proliferating or have recently exited the cell cycle. ${ }^{10}$ Conversely, apart from some neural and anterior pituitary cells, most non-proliferating cells do not express immunohistochemically detectable concentrations of stathmin. ${ }^{10}$ This would suggest that the protein has some function needed by proliferating cells. However, because most proliferating cells are simultaneously following a programme of differentiation, it is also possible that stathmin is involved in processes relating primarily to cell differentiation. These alternative possibilities may be investigated by studying stathmin expression in cell types, such as hepatocytes, that are fully differentiated but which retain the capacity to proliferate.

Normal adult mammalian liver, in which very few cells are proliferating, does not have detectable concentrations of stathmin protein ${ }^{1011}$ or messenger RNA (mRNA) ${ }^{212}$ In addition, hepatocytes positive for the protein by immunostaining are very infrequent. ${ }^{10}$ In contrast, experimental models of liver regeneration show marked increases in stathmin protein ${ }^{13}$ and mRNA, ${ }^{21314}$ as revealed by western and by northern blotting, respectively. However, the cellular localisation of stathmin cannot be demonstrated by such studies. It has been suggested that stathmin is induced in hepatocytes during this process, on the basis of differential cell extraction ${ }^{2}$ or in situ hybridisation. ${ }^{14}$ However, it is not certain whether it is only the proliferating hepatocytes that show stathmin upregulation during this process, as opposed to a more general change in stathmin synthesis by liver cells.

In this study stathmin expression in a wide variety of human liver disease conditions showing regeneration has been demonstrated by immunohistochemistry and quantitated by western blotting. In particular, the relation between stathmin expression and the proliferating cell populations was studied using double immunostains that simultaneously detect stathmin and the $\mathrm{Ki} 67$ antigen, a proliferation associated nuclear protein. ${ }^{1516}$

\section{Methods}

Representative blocks of formaldehyde fixed, paraffin wax embedded liver tissue from 31 different patients were studied. They were selected to represent a variety of different liver conditions showing variable degrees of hepatocyte regeneration, and are summarised in the table. Needle biopsy specimens were taken from three cases of acute transplant rejection. All of the other specimens were from hepatectomies. Fresh tissue that had been stored at 
Summary of the liver specimens used in this study

\begin{tabular}{lcc}
\hline Disease category & $\begin{array}{l}\text { No. with paraffin } \\
\text { wax embedded tissue }\end{array}$ & $\begin{array}{l}\text { No. with } \\
\text { frozen tissue }\end{array}$ \\
\hline Submassive necrosis $^{\mathrm{a}}$ & 6 & 5 \\
Paracetomol poisoning $_{\text {Primary biliary cirrhosis }}$ & 5 & 4 \\
Chronic hepatitis & 6 & 5 \\
Alcoholic cirrhosis & 5 & 5 \\
Wilson's disease & 4 & 3 \\
Acute transplant rejection & 2 & 0 \\
\hline Total & 3 & 0 \\
\hline
\end{tabular}

${ }^{a}$ These cases presented clinically as fulminant hepatitis of un known aetiology (viral markers for hepatitis A, B and C were negative); ${ }^{b}$ all five cases were end stage autoimmune chronic hepatitis with cirrhosis

$-70^{\circ} \mathrm{C}$ was available on 22 of these cases. Fresh tissue from three specimens of histologically normal liver was also studied.

Sections of the paraffin wax embedded tissues $(4 \mu \mathrm{m})$ were prepared for immunostaining on glass slides coated with 3-aminopropyltriethoxysilane (A3648; Sigma, Poole, Dorset, UK) and rehydrated by sequential immersion in xylene, alcohol and water. Endogenous peroxidase activity was blocked by placing the sections in $0.3 \%$ hydrogen peroxide in methanol for 30 minutes. Microwave antigen retrieval was performed as described previously. ${ }^{17}$ Briefly, slides were placed in Schieferdecker jars and immersed in one litre of $0.01 \mathrm{M}$ citrate buffer, $\mathrm{pH} 6.0$, at room temperature. This was heated in a household microwave oven at $750 \mathrm{~W}$ for 30 minutes. At the end of the heating period, the slides were removed from the hot buffer into water at room temperature. All slides were rinsed in $0.05 \mathrm{M}$ Tris buffered saline (TBS), pH 7·6. This buffer was used also to dilute all reagents and for all washes between incubations.

Sections were stained with a mixture of a rabbit antiserum against an amino-terminal 15 amino acid stathmin peptide, ${ }^{10}$ used at a dilution of 1 in 200, and MIB1 (0505; Immunotech, Marseilles, France), which recognises the Ki67 antigen, ${ }^{18}$ at a dilution of 1 in 50 . These antibodies were prepared in $10 \%$ normal sheep serum and applied to the sections for one hour. Following a wash in TBS, a mixture of a biotinylated goat antiserum against rabbit immunoglobulins (E 432; Dako, High Wycombe, UK), at a dilution of 1 in 200 , and of a horseradish peroxidase conjugated goat antiserum against mouse immunoglobulins (P 4471; Dako), at a dilution of 1 in 50 , was applied to the sections for 45 minutes. This was followed by a 45 minute incubation with a mixture of alkaline phosphatase conjugated Streptavidin biotin complex (K 391; Dako), at a dilution of 1 in 100 , and of a horseradish peroxidase conjugated goat antiserum against mouse immunoglobulins ( $P$ 447; Dako), at a dilution of 1 in 50 .

Labelling of cytoplasmic stathmin was visualised using an alkaline phosphatase chromogen prepared by mixing $10 \mathrm{mg}$ Naphthol-ASMX-phosphate (N5000; Sigma) in $1 \mathrm{ml} \mathrm{N}, \mathrm{N}$ dimethylformamide (D4254; Sigma) and $50 \mathrm{mg}$ Fast Red TR salt (F2768; Sigma) in $50 \mathrm{ml} 0.05 \mathrm{M}$ Tris buffer, $\mathrm{pH}$ 8.2. The slides were incubated in this chromogen solution for 15 minutes at room temperature. Slides were then covered with $1 \mathrm{mg} / \mathrm{ml}$ diaminobenzidine (D5905; Sigma) with $0.03 \% \mathrm{H}_{2} \mathrm{O}_{2}$ in TBS for five minutes, which stained $\mathrm{Ki} 67$ antigen positive nuclei brown. Sections were then counterstained in Mayer's haematoxylin for two minutes and then coverslipped using an aqueous mountant.

Control sections on each specimen were stained with the following combinations of antisera: rabbit antistathmin at a dilution of 1 in 200 together with a monoclonal antibody against rotavirus (tissue culture supernatant) at a dilution of 1 in 10 ; a 1 in 200 dilution of the rabbit antistathmin serum preincubated with the immunising peptide and MIB1 at a dilution of 1 in 50 ; and a 1 in 200 dilution of the rabbit antistathmin serum preincubated with the immunising peptide and the antibody against rotavirus at a dilution of 1 in 10 . In addition, one section was stained with the rabbit antiserum against stathmin followed by biotinylated goat antirabbit immunoglobulins (1 in 200), detected with alkaline phosphatase conjugated Streptavidin biotin complex ( 1 in $100)$ and visualised with the alkaline phosphatase chromogen. A further section from each case was stained with MIB1 ( 1 in 50), detected with horseradish peroxidase conjugated goat antimouse immunoglobulins ( 1 in 50) and visualised with diaminobenzidine as described above. With each immunostaining batch, positive control sections of normal tonsil were stained with the polyclonal antiserum to stathmin and inhibited antiserum.

Tissue protein samples for western blotting analysis were prepared by a method derived from Sobel et al. ${ }^{19}$ Tissue was resuspended in five volumes of homogenisation buffer which consisted of $10 \mathrm{mM}$ Tris $/ \mathrm{HCl}, \mathrm{pH} 7 \cdot 4,10 \mu \mathrm{g} /$ $\mathrm{ml}$ leupeptin, $25 \mu \mathrm{g} / \mathrm{ml}$ aprotinin, $10 \mu \mathrm{g} / \mathrm{ml}$ pepstatin, and $1 \mathrm{mM}$ EDTA. The tissue was homogenised and the nuclei pelleted by centrifugation at $3000 \mathrm{rpm}$ for 15 minutes (MSE Mistral 2L). The resultant supernatant fluid was adjusted to $0 \cdot 1 \mathrm{M} \mathrm{NaCl}$ and heated to $90^{\circ} \mathrm{C}$ for 10 minutes. Heat precipitated proteins were pelleted by microcentrifugation at $13000 \mathrm{rpm}$ for 30 minutes. Protein in the resultant supernatant fluid, which included stathmin, was concentrated by freeze drying. Positive control samples of protein were prepared from exponentially growing HL60 cells, which are known to contain high concentrations of stathmin. ${ }^{1}$

Protein from each sample $(150 \mu \mathrm{g})$ was loaded on to sodium dodecyl sulphate (SDS) polyacrylamide electrophoresis gels as described previously. ${ }^{10}$ Proteins were electrophoretically transferred on to nitrocellulose filters. Membranes were initially blocked with $2.5 \%(\mathrm{w} / \mathrm{v})$ skimmed milk in $0.1 \mathrm{M}$ phosphate buffered saline, $\mathrm{pH} 7 \cdot 2$, for one hour. They were then stained for the presence of stathmin by using the rabbit antisera described above at a dilution of 1 in 500. This primary antibody incubation step was carried out overnight at $4^{\circ} \mathrm{C}$. Antibody binding to the filters was revealed by incubation with $0.1 \mu \mathrm{Ci} / \mathrm{ml}{ }^{125} \mathrm{I}$ labelled protein A (Amersham, Little Chalfont, UK) for two hours at room temperature. Auto- 
radiography was then performed for four days at $-80^{\circ} \mathrm{C}$ using preflashed films. Autoradiographs were scanned using a laser densitometer and analysed with Gelscan XL software.

\section{Results}

Positive immunostaining for stathmin was seen in the previously described distribution ${ }^{10}$ in the positive control tonsil sections. There was no immunostaining on tonsil tissue stained with the antistathmin serum that had been incubated with the immunising peptide.

A proportion of hepatocytes and other cell types stained for stathmin and the $\mathrm{Ki} 67$ antigen in all 31 liver specimens studied. The proportion and distribution of cells staining for the two proteins in the sections stained for both antigens simultaneously were similar to that seen in the sections stained for stathmin alone and for Ki67 antigen alone. There was no positive immunostaining in the negative control sections. Similarly, there was no evidence for cross-reactivity between the primary and detection system reagents on the sections stained simultaneously with one test antibody and one control reagent. Some specimens showed weak diffuse background staining of hepatocytes consistent with endogenous biotin.

The proportion of hepatocytes showing cytoplasmic positivity for stathmin was assessed semiquantitatively. In some specimens there were only occasional scattered hepatocytes that were immunopositive for stathmin. Others showed staining of up to $20 \%$ of hepatocytes. The stain intensity in positive hepatocytes

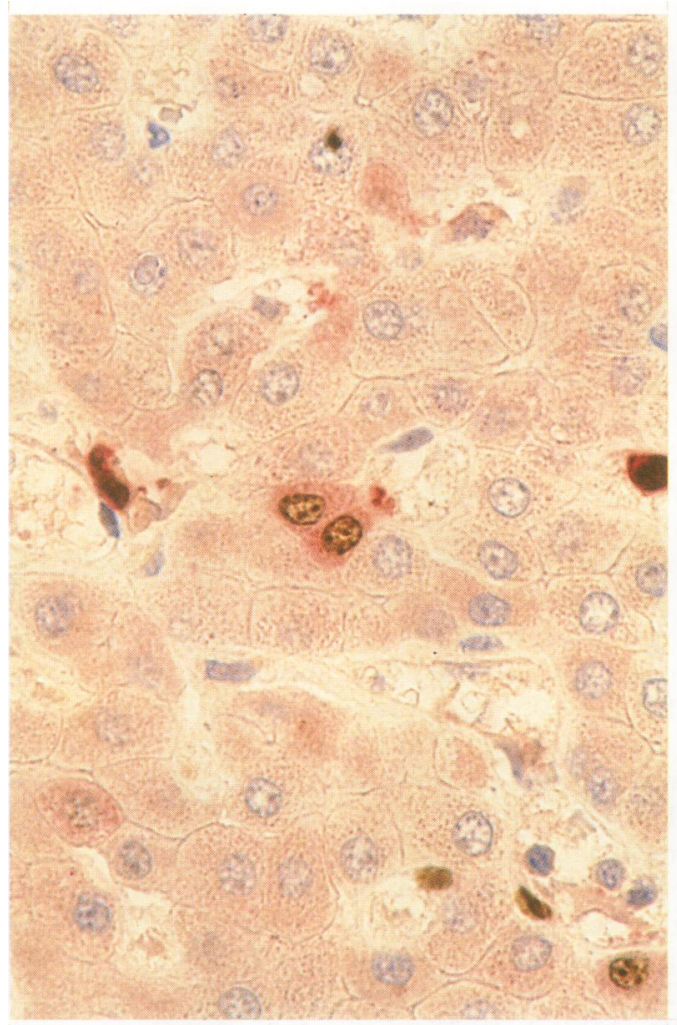

Figure 1 A pair of hepatocytes show cytoplasmic positivity for stathmin (red) and nuclear positivity for the Ki67 antigen (brown). Neighbouring hepatocytes are negative for both antigens.

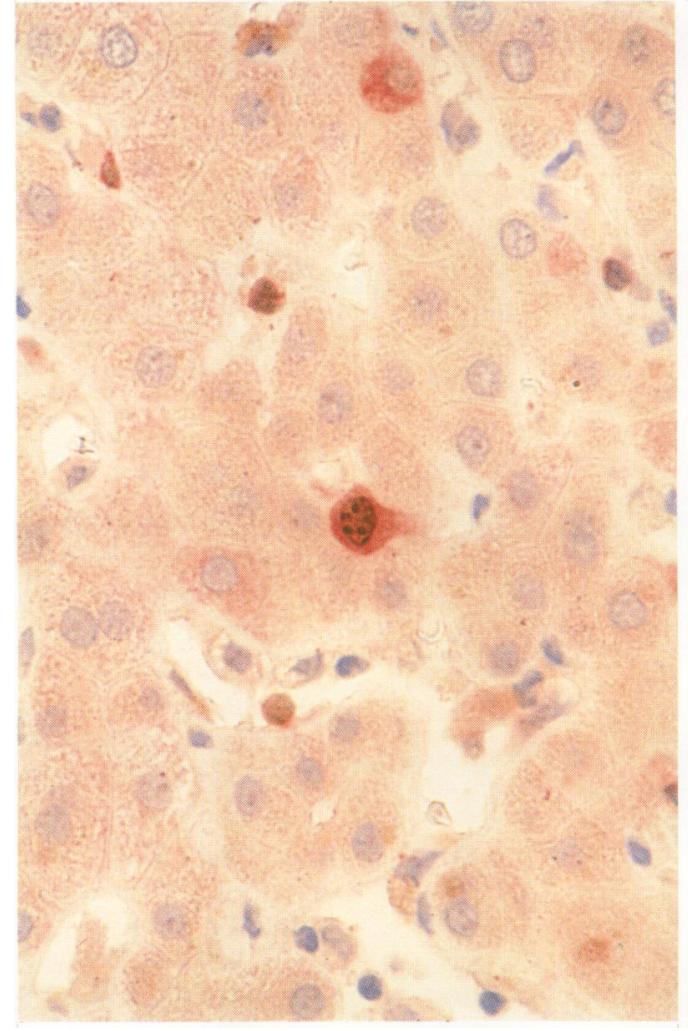

Figure 2 Another liver specimen showing co-localisation of stathmin and the Ki67 antigen in a central hepatocyte. Two lymphocytes in this field are also positive for both proteins.

tended to be weaker than that seen in positively stained lymphoid cells on the same sections. Stathmin positive hepatocytes were scattered widely throughout the regions of liver acini. Most of these positive cells were large, fully differentiated hepatocytes that were morphologically indistinguishable from their unstained neighbours. There was no apparent relation between the proportion of stathmin positive hepatocytes and disease category. However, the number of individual cases in each group was too small for accurate assessment of any difference between the groups.

Most stathmin positive hepatocytes showed nuclear immunostaining for the Ki67 antigen (figs 1 and 2). In some specimens a small proportion of cells were stathmin positive but Ki67 antigen negative, but these were infrequent compared with the numbers of cells positive for both antigens or negative for both antigens. Thus, in all specimens there was the same close relation between expression of stathmin and the Ki67 antigen that has been observed previously in normal tissues. ${ }^{10}$

All of the stained sections also showed variable numbers of inflammatory cells. A proportion of lymphoid cells were strongly positive for stathmin. This was particularly true for germinal centre cells in those cases with lymphoid follicles and for larger lymphoid cells with morphology consistent with that of $T$ cell blasts. Positively stained lymphoid cells were particularly prominent in cases of acute rejection and submassive necrosis compared with the other disease groups. As has been described previously in normal lymphoid tissue ${ }^{10}$ there was a close correlation between expression of 


\section{A в C D E F G H Mr (kDa)}

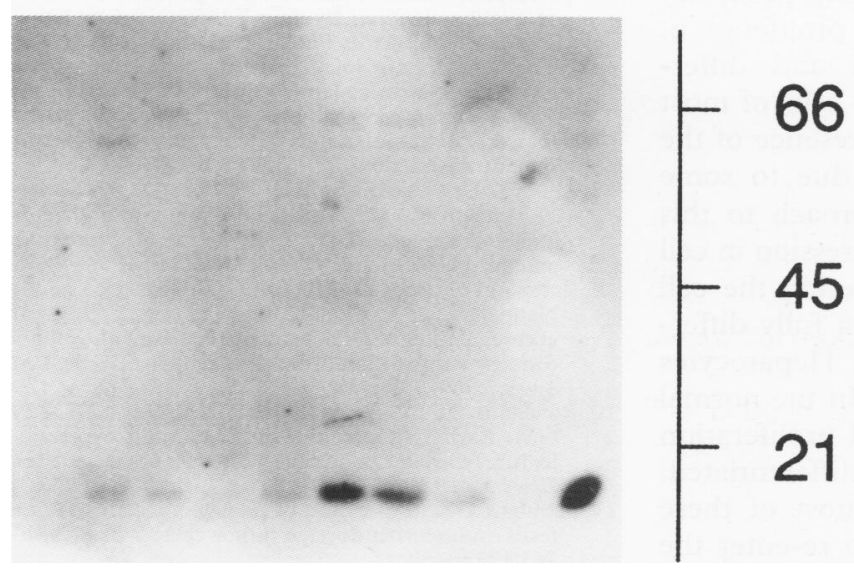

Figure 3 Western blot showing the presence of a band of variable intensity representing a $19 \mathrm{kDa}$ protein in seven of the liver specimens studied (lanes $A$ to $G$ ). Lane $H$ is $a$ cytoplasmic extract from HL60 cells (positive control).

stathmin and of the Ki67 antigen in these lymphoid cells.

All specimens also showed small numbers of stathmin positive endothelial cells, epithelial cells lining small bile ducts and sinusoidal cells with the morphology of Kupffer cells. In those specimens with bile ductular proliferation small numbers of ductular epithelial cells were positive for stathmin. Again, there was a close relation between the expression of the two antigens studied in these cell types.

In all of the cases of liver disease western blotting of extracts showed a predominant band at $19 \mathrm{kDa}$ that is consistent with stathmin (fig 3). A $19 \mathrm{kDa}$ band was not seen in the samples of normal liver. Extra, minor bands of higher molecular weight proteins were seen in some specimens, as has been described previously with this antiserum. ${ }^{10}$ However, these bands were always quantitatively weaker than that at $19 \mathrm{kDa}$. Thus, the immunopositivity seen with the polyclonal antiserum was consistent with the presence of stathmin, rather than being because of cross-reactivity of the antiserum with unrelated antigens. Although there was a trend for specimens with many stathmin immunopositive hepatocytes to have higher amounts of the protein on western blotting, this was not seen in each individual case. However, this comparison is complicated by the variable numbers of positive lymphoid and other cells. In addition, it is likely that heterogeneity in the distribution of proliferating hepatocytes between different sites in the liver accounts for some of the variation seen between the subjective assessment of stathmin positive cells and western blot quantitation, which were performed on samples from different sites of each hepatectomy specimen.

\section{Discussion}

Several groups have described independently the protein termed stathmin in this paper. ${ }^{1-720}$ These groups first identified the protein in a variety of cell types and most have focused their attention on stathmin phosphorylation following a variety of physiological stimuli. The co-identity of the protein described by these groups has since been proven by homology of the cDNA and amino acid sequence, electrophoretic mobility of the multiple phosphoforms and reactivity with specific antisera. The different theories that have been proposed for the protein's function account for the variety of names that have been applied. Thus, prosolin $^{1}$ is derived from in the cytosol of proliferating cells. Metablastin has been proposed by the group who have suggested that the protein is important in development and cell differentiation. ${ }^{2}$ Sobel proposed the term stathmin from stathmos, meaning relay, and suggested that the protein has a role in signal transduction in a wide variety of cellular processes. ${ }^{7}$ Other groups have proposed that the protein is important in malignant transformation and use descriptive terms such as oncoprotein 18 and leukaemia associated protein $18 .^{4-68}$ While the exact function of the protein remains unknown, there would be an advantage to using the simple designation of p19. The present authors adhere to the term stathmin because this is the one most used in current publications.

A number of observations support the hypothesis that stathmin is important in processes relating to cell proliferation. There is upregulation of the protein in lymphoid cells when they are induced to proliferate. ${ }^{321-23}$ Conversely, stathmin concentrations decrease following growth arrest of cells. ${ }^{22425}$ Inhibition of stathmin mRNA in peripheral blood lymphocytes, by antisense oligonucleotides, results in delayed entry into $S$ phase. ${ }^{24}$ There is increased phosphorylation of the protein in a variety of cell types following stimuli that result in cell growth arrest. ${ }^{26}$ It has been shown that phosphorylation of stathmin relates to cell cycle progression. ${ }^{23}$ The protein has been shown to be a direct substrate in vitro for cyclic AMP dependent protein kinase, p34 $4^{c d c 2}$ and MAP kinase. ${ }^{2728}$ The above studies were performed using a small collection of cell lineages. However, immunohistochemical studies on normal tissues show that immunopositivity for stathmin is confined to the proliferating cell compartments in nearly all cell lineages. ${ }^{10}$

Many papers have described changes in the phosphorylation status of stathmin in endocrine cells following stimuli that result in hormone secretion. ${ }^{7}$ However, these studies have been performed in vitro on growing cultures, which would be expected to express stathmin, and factors involved in hormone secretion often have an additional trophic function. Thus, the apparent relation between stathmin phosphorylation and hormone secretion in these experimental models may be coincidental.

The proposed relations between stathmin expression and development and cell differentiation are largely the result of studies on the nervous system, ${ }^{27}$ in which stathmin expression occurs in a proportion of non-proliferating cells, including some fully differentiated neurones. ${ }^{10}$ The relation between stathmin and 
differentiation in other cell lineages may simply be because differentiating cells are also usually proliferative. Thus, it is the opinion of the authors that stathmin has a function necessary for some process related to cell proliferation. However, because proliferation and differentiation are so closely linked in cells of most lineages, it is possible that the presence of the protein in proliferating cells is due to some role in differentiation. One approach to this problem is to study stathmin expression in cell types that are capable of re-entering the cell cycle despite normally being in a fully differentiated, non-proliferating state. Hepatocytes represent one such cell lineage. In the normal adult liver there is very little cell proliferation and most hepatocytes are in a differentiated, post-mitotic state. ${ }^{29}$ However, most of these hepatocytes have the capacity to re-enter the cell cycle and undergo a small number of cell divisions. ${ }^{29} \mathrm{~A}$ description of stathmin expression in hepatocytes would thus indicate if the protein is primarily involved in proliferation or in differentiation. Although several papers have described upregulation of stathmin concentrations in experimental models of liver regeneration, none of these had unequivocally demonstrated that stathmin expression is confined to proliferating hepatocytes. ${ }^{211-14}$

In this study we have used cases of human liver disease as a source of regenerating hepatocytes. Irrespective of the particular disease process, it was demonstrated that stathmin expression in hepatocytes correlated closely with expression of the Ki67 antigen. Although the exact function of Ki67 antigen remains unknown, it is expressed in all phases of the cell cycle and has a very short half life and so is lost quickly following exit from the cell cycle. Immunostaining for this antigen with a number of immunohistochemical reagents has thus become a robust method of demonstrating proliferating cells in tissue sections. Co-expression of stathmin with the $\mathrm{Ki} 67$ antigen in all the clinical specimens studied is strong evidence for stathmin being upregulated in proliferating hepatocytes. These proliferating cells retain the morphological appearance of their differentiated, non-cycling, stathmin negative neighbours. These observations suggest that stathmin has a function important for cell proliferation, rather than some process specific to cell differentiation.

This study was supported by the Leukaemia Research Fund and the Endowment Fund of the former United Birmingham Hospitals.

1 Braverman R, Bhattacharya B, Feuerstein N, Cooper HL. Identification and characterization of the nonphosphorylated precursor of $\mathrm{pp} 17$, a phosphoprotein associated with phorbol ester induction of growth arrest and monocytic differentiation in HL-60 promyelocytic leukemia cells. f Biol Chem 1986;261:14342-8.

2 Schubart UK, Xu J, Fan W, Cheng G, Goldstein H, Alpini $\mathrm{G}$, et al. Widespread differentiation stage-specific expression of the gene encoding phosphoprotein p19 (metablastin) in mammalian cells. Differentiation 1992;51: 21-32.

3 Gullberg M, Noreus K, Brattsand G, Friedrich B, Shingler $V$. Purification and characterization of a 19-kilodalton intracellular protein. An activation-regulated putative protein kinase $\mathrm{C}$ substrate of $\mathrm{T}$ lymphocytes. $\mathcal{F}$ Biol Chem 1990;265:17499-505.
4 Hanash SM, Strahler JR, Kuick R, Chu EHY, Nichols D. Identification of a polypeptide associated with the malignant phenotype in acute leukemia. $\mathcal{F ~ B i o l ~ C h e m ~ 1 9 8 8 ; ~}$ 263:12813-15.

5 Peyron JF, Aussel C, Ferrua B, Haring H, Fehlmann M. Phosphorylation of two cytosolic proteins. An early event Phosphorylation of two cytosolic proteins. An ear

6 Mock BA, Krall MM, Padlan C, Dosik JK, Schubart UK. The gene for Lap1 8, leukemia-associated phosphoproteinp18 (metablastin), maps to distal mouse chromosome 4 Mamm Genome 1993;4:461-2.

7 Sobel A. Stathmin: a relay phosphoprotein for multiple signal transduction? TIBS 1991;16:301-5.

8 Zhu XX, Kozarsky K, Strahler JR, Eckerskorn C, Lottspeich $\mathrm{F}$, Melhem R, et al. Molecular cloning of a novel human leukemia-associated gene. Evidence of conservation in animal species. $\mathcal{f} \mathrm{Biol}$ Chem 1989;264:14556-60.

9 Brattsand G, Roos G, Marklund U, Ueda H, Landberg G, Nanberg E, et al. Quantitative analysis of the expression Nanberg $E$, et al. Quantitative analysis of the expression
and regulation of an activation-regulated phosphoprotein (oncoprotein 18) in normal and neoplastic cells. Leukemia 1993;7:569-79.

10 Rowlands DC, Williams A, Jones NA, Guest SS, Reynolds GM, Barber PC, et al. Lap18/stathmin expression is a feature of proliferating cells of most, if not all, cell lineages. Lab Invest 1995;72:100-13.

11 Schubart UK. Expression of phosphoprotein p19 in brain, testis and neuroendocrine tumor cells. F Biol Chem 1988; 263:12156-60

12 Schubart UK, Das Banerjee M, Eng J. Homology between the cDNAs encoding phosphoprotein p19 and SCG10 reveals a novel mammalian gene family preferentially expressed in developing brain. DNA 1989;8:389-98.

13 Koppel J, Loyer P, Maucuer A, Rehak P, Manceau V, GuyenGuillouzo, et al. Induction of stathmin expression during liver regeneration. FEBS Lett 1993;331:65-70.

14 Okazaki T, Himi T, Peterson C, Mori N. Induction of stathmin mRNA during liver regeneration. FEBS Lett 1993;336:8-12.

15 Gerdes J, Schwab U, Lemke H, Stein H. Production of a mouse monoclonal antibody reactive with a human nuclear antigen associated with cell proliferation. Int $f$ Cancer 1983;31:13-20.

16 Gerdes J, Li L, Schlueter C, Duchrow M, Wohlenberg $\mathrm{C}$, Gerlach $\mathrm{C}$, et al. Immunobiochemical and molecular biologic characterization of the cell proliferation-associated nuclear antigen that is defined by monoclonal antibody Ki-67. Am $\mathcal{F}$ Pathol 1991;138:867-73.

17 Harrison RF, Reynolds GM, Rowlands DC. Immunohistochemical evidence for the expression of proliferating cell nuclear antigen (PCNA) by non-proliferating hepatocytes adjacent to metastatic tumours and in inflammatory conditions. F Pathol 1993;171:115-22.

18 Cattoretti G, Becker MHG, Key G, Duchrow M, Schluter $\mathrm{C}$, et al. Monoclonal antibodies against recombinant parts of the Ki-67 antigen (MIB 1 and MIB 3) detect proof the Ki-67 antigen (MIB 1 and MIB 3 ) detect proparaffin sections. $\mathcal{f}$ Pathol 1992;168:357-63.

19 Sobel A, Boutterin M-C, Beretta L, Chneiweiss H, Doye $\mathrm{V}$, Peyro-Saint-Paul $\mathrm{H}$. Intracellular substrates for extracellular signalling. Characterization of a ubiquitous, neuron-enriched phosphoprotein (stathmin). f Biol Chem 1989;264:3765-72.

20 Lord JM, Wong AKY, Brown G. Changes in phosphoproteins during commitment of HL60 cells to monocyte differentiation: evidence for multiple protein kinase involvement. Exp Hematol 1988;16:620-6.

21 Cooper HL, McDuffie E, Braverman R. Human peripheral lymphocyte growth regulation and response to phorbol esters is linked to synthesis and phosphorylation of the esters is linked to synthesis and phosphorylation of the
cytosolic protein, prosolin. F Immunol 1989;143:956-63.

22 Melhem RF, Zhu X-X, Hailat N, Strahler JR, Hanash SM Characterization of the gene for a proliferation-related phosphoprotein (oncoprotein 18) expressed in high amounts in acute leukemia. $\mathcal{F ~ B i o l ~ C h e m ~ 1 9 9 1 ; 2 6 6 : 1 7 7 4 7 - ~}$ 53.

23 Strahler JR, Lamb BJ, Ungar DR, Fox DAS, Hanash SM. Cell cycle progression is associated with distinct patterns of phosphorylation of Op18. Biochem Biophys Res Commun 1992;185:197-203.

24 Melhem RF, Strahler JR, Hailat N, Zhu XX, Hanash SM. Involvement of Op 18 in cell proliferation. Biochem Biophys Involvement of Op18 in cell prolifer

25 Brown G, Bunce CM, Rowlands DC, Williams GR. Alltrans retinoic acid and 1a,25-dihydroxyvitamin D3 cooperate in vitro to promote differentiation of the human promyeloid leukemia cell line HL60 to monocytes. Leukemia 1994;8:806-15.

26 Jones NA, Lord JM, Brown G. Changes in the phosphorylation status of a $19 \mathrm{kDa}$ cytosolic protein are linked to the growth arrest of HL60 cells. Leuk Res 1992;16: 353-61.

27 Beretta L, Dobransky T, Sobel A. Multiple phosphorylation of stathmin: identification of 4 sites phosphorylated in intact cells and in vitro by cyclic AMP dependent protein kinase and p34cdc2. F Biol Chem 1993;268:20076-84.

28 Markland U, Brattsand G, Shingler V, Gullberg M. Serine 25 of oncoprotein 18 is a major cytosolic target for the mitogen-activated protein kinase. $f$ Biol Chem 1993;268. 15039-49.

29 Michalopoulos GK. Liver regeneration: molecular mechanisms of growth control. FASEB 7 1990;4:176-87. 